\title{
Effect of ship locking on sediment oxygen uptake in impounded rivers
}

\author{
A. Lorke, ${ }^{1}$ D. F. McGinnis, ${ }^{2,3}$ A. Maeck, ${ }^{1}$ and H. Fischer ${ }^{4}$ \\ Received 1 June 2012; revised 5 October 2012; accepted 29 October 2012; published 14 December 2012.
}

[1] In the majority of large river systems, flow is regulated and/or otherwise affected by operational and management activities, such as ship locking. The effect of lock operation on sediment-water oxygen fluxes was studied within a $12.9 \mathrm{~km}$ long impoundment at the Saar River (Germany) using eddy-correlation flux measurements. The continuous observations cover a time period of nearly 5 days and 39 individual locking events. Ship locking is associated with the generation of surges propagating back and forth through the impoundment which causes strong variations of near-bed current velocity and turbulence. These wave-induced flow variations cause variations in sediment-water oxygen fluxes. While the mean flux during time periods without lock operation was $0.5 \pm 0.1 \mathrm{~g} \mathrm{~m}^{-2} \mathrm{~d}^{-1}$, it increased by about a factor of 2 to $1.0 \pm 0.5 \mathrm{~g} \mathrm{~m}^{-2} \mathrm{~d}^{-1}$ within time periods with ship locking. Following the daily schedule of lock operations, fluxes are predominantly enhanced during daytime and follow a pronounced diurnal rhythm. The driving force for the increased flux is the enhancement of diffusive transport across the sediment-water interface by bottom-boundary layer turbulence and perhaps resuspension. Additional means by which the oxygen budget of the impoundment is affected by lock-induced flow variations are discussed.

Citation: Lorke, A., D. F. McGinnis, A. Maeck, and H. Fischer (2012), Effect of ship locking on sediment oxygen uptake in impounded rivers, Water Resour. Res., 48, W12514, doi:10.1029/2012WR012483.

\section{Introduction}

[2] About $60 \%$ of the world's large river systems are dammed or impounded [Nilsson et al., 2005]. Besides hydropower generation, irrigation, and flood control, damming of rivers to support cargo ship navigation is among the major purposes of these constructions. In Germany, for example, about 4900 river $\mathrm{km}$ are maintained as federal inland waterways, of which $1960 \mathrm{~km}$ are free-flowing and $2940 \mathrm{~km}$ are impounded (Federal Waterways and Shipping Administration, www.wsv.de). These waterways include approximately 250 weirs (unpublished data provided by the Federal Waterways and Shipping Administration) and an even higher number of ship locks [Stamm, 2003]. The weirs are used to maintain a system-specific minimum depth for cargo ship navigation. The increased water depth and associated reduction in flow velocity compared to natural flow conditions lead to a number of changes in ecosystem functioning and services including sediment retention, development of phytoplankton, nutrient cycling, and oxygen

\footnotetext{
${ }^{1}$ Institute for Environmental Sciences, University of Koblenz-Landau, Landau, Germany.

${ }^{2}$ GEOMAR, Helmholtz Centre for Ocean Research, Kiel, Germany.

${ }^{3}$ University of Southern Denmark, Institute of Biology, Nordic Center for Earth Evolution (NordCee), Denmark.

${ }^{4}$ Federal Institute of Hydrology, Koblenz, Germany.

Corresponding author: A. Lorke, Institute for Environmental Sciences, University of Koblenz-Landau, Fortstrasse 7, 76829 Landau, Germany. (lorke@uni-landau.de)

C2012. American Geophysical Union. All Rights Reserved. 0043-1397/12/2012WR012483
}

budget [McGinnis et al., 2006; Bosch and Allan, 2008]. Dissolved oxygen (DO) depletion and the occurrence of hypoxia are among the major ecological threats in impounded rivers subject to substantial organic sediment accumulation [Kittrell et al., 1959; Rosenberg et al., 1995; Friedl and Wuest, 2002].

[3] The DO balance in impoundments is mainly determined by oxygen production by net photosynthesis, advective transport through inflowing water, and atmospheric reaeration; while oxygen depletion is due to sediment oxygen uptake and biological and chemical oxygen consumption within the water column. The gas-transfer velocity of oxygen at the atmosphere-water interface, which determines the areal air-water flux for a given concentration gradient or deviation from equilibrium concentration (saturation), is controlled by near-surface turbulence at the water side of the interface [Lorke and Peeters, 2006]. With decreasing flow velocities and increasing depths, near-surface turbulence in low-gradient river systems and impoundments is increasingly controlled by wind speed rather than by mean flow velocity [Alin et al., 2011].

[4] Analogous to the air-water interface, DO transfer at the sediment-water interface can be described by the product of a transfer velocity and the concentration gradient across the interface [Grant and Marusic, 2011]. In systems with high sedimentation rates of organic matter and corresponding high sediment oxygen demand, the transfer velocity of DO at the sediment-water interface is controlled by bottom water velocity and benthic boundary layer turbulence, where the DO flux decreases with decreasing flow velocity [Lorke et al., 2003]. This leads to a decoupling of the driving forces for air-water and sediment-water fluxes 
with increasing flow depth, resulting in a situation where faster flow velocity increases the rate of sediment oxygen uptake, but not necessarily the atmospheric aeration rate.

[5] At the sediment-water interface, the transfer velocity not only dictates the oxygen flux into the sediment, but also the flux of reduced substances, e.g., $\mathrm{NH}_{4}^{+}$, dissolved $\mathrm{CH}_{4}$, and dissolved organic carbon, from the sediment side into the water and therewith affects also chemical and biological oxygen consumption within the water column [Matzinger et al., 2010]. The magnitude of these fluxes and their dependence on physical controls are essential for the understanding and prediction of the oxygen budget in rivers and impoundments.

[6] Direct estimates of aquatic sediment oxygen uptake rates are often restricted to ex situ or invasive measurements using, e.g., benthic chambers and in situ microprofiles or measurements performed with sediment cores (incubations or microprofiling) brought to the surface or into the laboratory. Such measurements, however, exclude the significant effect of in situ flow velocity and bottom-boundary layer turbulence on sediment-water fluxes [Lorke et al., 2003; Reidenbach et al., 2010]. Available in situ techniques include microprofiling at the sediment-water interface [Archer et al., 1989] and eddy-correlation measurements of turbulent vertical oxygen fluxes in the benthic boundary layer directly above the sediment surface [Berg et al., 2003]. The latter technique is increasingly used for estimating sediment-water fluxes in aquatic systems [Brand et al., 2008; McGinnis et al., 2008; Glud et al., 2010] because it provides areal averages of vertical fluxes [Berg et al., 2007] with a high temporal resolution from autonomous instrument deployments, includes and resolves the natural hydrodynamics, and is applicable to study sites where traditional methods are less feasible (fluffy or permeable sediments, etc).

[7] Here we analyze a 4 day long high-resolution eddycorrelation data set to extract the sediment-water oxygen flux in the Saar, a heavily impounded river in southwest Germany. We discuss the temporal variability of the oxygen uptake rate and reveal that the frequency of ship locking provides the dominant physical control for the observed variability.

\section{Study Site and Measurements}

\subsection{Study Site}

[8] The Saar River originates in the Vosges Mountains (France) and flows for $246 \mathrm{~km}$ into the Moselle River in Germany. Its total catchment area is $7431 \mathrm{~km}^{2}$. The lowest $90 \mathrm{~km}$ of the river is heavily impounded and was reconstructed between 1977 and 2000 for shipping purposes and hydropower generation. There are six weirs with ship locks with a total storage height of $55 \mathrm{~m}$. The mean water depth and discharge are $4.2 \mathrm{~m}$ and $80 \mathrm{~m}^{3} \mathrm{~s}^{-1}$, and flow velocities are reduced to or below $0.1 \mathrm{~m} \mathrm{~s}^{-1}$. In the deeper impoundments, large water depth and low flow velocities result in diurnal thermal stratification and low DO during summer, when oxygen concentration frequently falls below $4 \mathrm{mg} \mathrm{L}^{-1}$ [Becker et al., 2010].

[9] The data presented here were collected from 8 to 12 September 2010 in the Saar, approximately $19.8 \mathrm{~km}$ upstream of the confluence with the Moselle. A benthic lander system was deployed $1.3 \mathrm{~km}$ upstream of the Serrig Dam on the inner slope (3.1 m water depth) of a $180^{\circ}$ river bend (Figure 1a). Water temperature during sampling was $17^{\circ} \mathrm{C}$ (min. $16.5^{\circ} \mathrm{C}$; $\max .17 .5^{\circ} \mathrm{C}$ ). The fine sediments that accumulated in this lower section of the impoundment have an organic matter content (loss on ignition) of $10 \%$ of the dry mass (V. Kirchesch, personal communication).

[10] The schedule of lock operation upstream and downstream of the sampling site (impoundments Mettlach and Serrig, respectively) was provided by the Waterways and Shipping Office Saarbrücken.

\subsection{Measurements and Analyses}

\subsubsection{Instrumentation}

[11] The deployed benthic eddy correlation lander consists of an acoustic Doppler velocimeter (ADV, Nortek
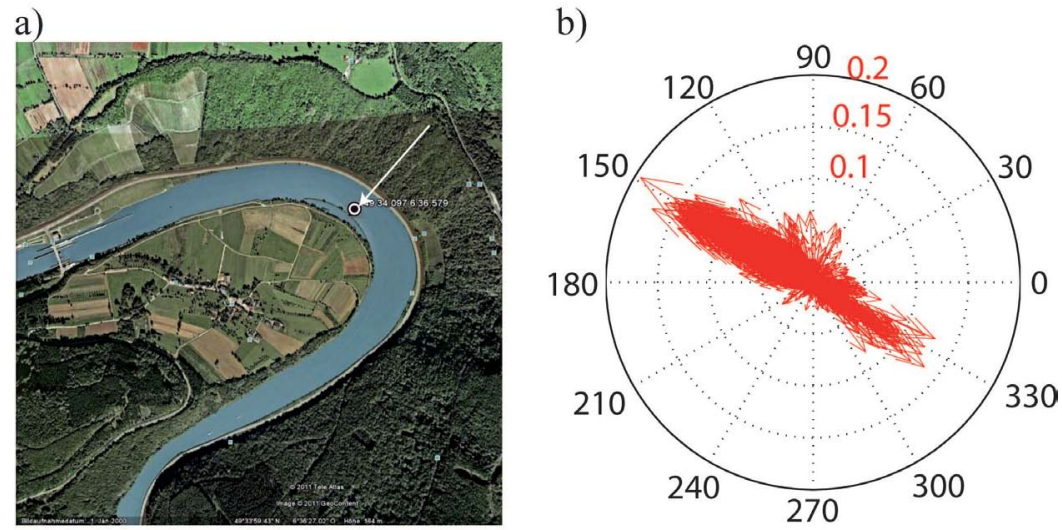

Figure 1. Left panel: Location of the sampling site $\left(\mathrm{N} 49^{\circ} 34.097^{\prime}\right.$, E $6^{\circ} 36.579^{\prime}$; indicated by white arrow (image courtesy of GoogleMaps). River flow direction is toward the west. The construction near the western edge of the map is the dam with two ship locks and the hydropower plant Serrig, located approximately $1.3 \mathrm{~km}$ downstream of the sampling site. Right panel: Compass plot of the average velocities in earth coordinates (right panel). Direction is measured in degrees relative to the east direction and the length of the velocity vectors is indicated in $\mathrm{m} \mathrm{s}^{-1}$. 
Vector), measuring the three-dimensional current velocity within a cylindrical sampling volume $0.15 \mathrm{~m}$ distant from the transducer (positioned $0.32 \mathrm{~m}$ above the sediment surface), and a Clark-type oxygen microelectrode (approximately $10 \mu \mathrm{m}$ tip diameter and $\sim 0.2 \mathrm{~s}$ response time) positioned in close vicinity of the ADV sampling volume (see McGinnis et al. [2011] for photo (their Figure 4B) and description). The sensor signal was converted to voltage using a picoamplifier connected to the analog input channel of the ADV. Data were recorded at $32 \mathrm{~Hz}$, but averaged to $8 \mathrm{~Hz}$ for all subsequent analyses. As demonstrated by A. Lorke, D. F. McGinnis, and A. Maeck (Eddy-correlation measurements of benthic fluxes under complex flow conditions in non-flat environments: Effects of coordinate transformations and averaging time scales, submitted to Limnology and Oceanography: Methods, 2012; henceforth Lorke et al., submitted), this downsampling did not result in any significant loss in the calculated flux. In addition to the eddy-correlation system, the lander was equipped with an optode (D-Opto, Envco) measuring oxygen concentration at a sampling interval of $60 \mathrm{~s}$, and a temperature and depth logger (TDR-1060, RBR) sampling every $10 \mathrm{~s}$. The optode oxygen data are used to convert the microelectrode readings from voltage (counts) to oxygen concentration by performing a linear regression on both data sets over the entire measurement period.

[12] The ADV also recorded the echo intensity of the transmitted ultrasonic ping caused by backscattering within the sampling volume. The intensity is provided in digital counts, which are converted to acoustic backscatter in $\mathrm{dB}$ by multiplying by a factor of 0.45 (Technical Notes No. 3, Nortek AS, www.nortek-as.com/lib/technical-notes/seditments).

\subsubsection{Eddy-Correlation Oxygen Fluxes}

[13] By neglecting horizontal flux divergence and storage terms and by assuming a homogeneous sink of oxygen which is restricted to the sediment surface, the vertical component of the turbulent flux of dissolved oxygen can be considered as a measure of the sediment oxygen uptake rate [Berg et al., 2003]. The turbulent vertical flux of oxygen above the sediment $F_{\mathrm{O} 2}$ can be estimated from cross correlation of velocity and oxygen concentration fluctuations $w^{\prime}$ and $C^{\prime}$, respectively:

$$
F_{\mathrm{O} 2}=\overline{w^{\prime} C^{\prime}}
$$

where the overbar denotes temporal averaging. The fluctuating components $w^{\prime}$ and $C^{\prime}$ are obtained by subtracting a temporal mean value from the measured vertical velocities $w(t)$ and oxygen concentrations $C(t)$, respectively $[w(t)=$ $\left.\bar{w}+w^{\prime}(t) ; C(t)=\bar{C}+C^{\prime}(t)\right]$. Besides technical issues, e.g., response time corrections for the oxygen concentration measurements [McGinnis et al., 2008; Lorrai et al., 2010], application of the eddy-flux concept to single-point measurements requires careful consideration of the coordinate system (i.e., the direction of the flux), as well as the choice of time scales for separating mean and fluctuating concentration and velocity components and for averaging their cross correlation [McGinnis et al., 2008]. Based on the long-term data set obtained at the Saar, these methodological issues are discussed in a companion paper (Lorke et al., submitted) in greater detail. The most robust flux estimates were obtained by rotating the measured three-dimensional velocity vectors using the planar fit method [Wilczak et al., 2001] in order to obtain a vertical velocity component which is normal to the local stream line. Vertical oxygen fluxes were estimated from cross correlation of vertical velocity and oxygen concentration fluctuations for time intervals of $512 \mathrm{~s}(\sim 8.5 \mathrm{~min})$, respectively. Oxygen concentration fluctuations $C^{\prime}$ were obtained by subtracting a $512 \mathrm{~s}$ running average from the measured concentration time series.

\subsubsection{Turbulence}

[14] Dissipation rates of turbulent kinetic energy were estimated using the inertial dissipation technique [Lorke and Wüest, 2005; Bluteau et al., 2011]. Wave number spectra of vertical velocity fluctuations, obtained using Taylor's frozen turbulence hypothesis for each $512 \mathrm{~s}$ long data segment, were fitted to the corresponding inertial subrange of the universal Kolmogorov turbulence spectrum. The selection of wave number range for spectral fitting and validation of obtained dissipation rates are based on the recommendations provided by Bluteau et al. [2011]. The vertical velocity component showed lower noise levels than the horizontal components and the corresponding spectra allowed for valid dissipation rate estimates also during low flow conditions (1-2 $\left.\mathrm{cm} \mathrm{s}^{-1}\right)$.

\section{Results}

\subsection{Flow Dynamics}

[15] Discharge during the measurements ranged between 37 and $68 \mathrm{~m}^{3} \mathrm{~s}^{-1}$ with a mean of $51 \mathrm{~m}^{3} \mathrm{~s}^{-1}$ (data source: German Federal Waterways and Shipping Administration). The dynamics of current velocity, water level, and DO concentration are depicted in Figure 2. Mean current magnitude and standard deviation was $3.7 \pm 2.5 \mathrm{~cm} \mathrm{~s}^{-1}$ with the mean velocity mostly aligned in the longitudinal direction (Figure $1 \mathrm{~b})$. Short-term $(<1 \mathrm{~h})$ velocity fluctuations, however, can exceed magnitudes of $15 \mathrm{~cm} \mathrm{~s}^{-1}$ in both the downstream and upstream directions. These velocity fluctuations are associated with fluctuations in water level of up to $20 \mathrm{~cm}$ and predominantly occur during daytime when the ship locks were operated (Figure 2a). These fluctuations are caused by surges, generated by the intake or discharge of the ship locks, traveling back and forth through the impoundment and being reflected at both ends. Figure $2 b$ exemplifies two of these waves observed in the morning of 10 September. The first one is a negative surge (hour $10: 40$ ), generated by filling the lock at Serrig, located 1.3 $\mathrm{km}$ downstream of the sampling site. The second wave (hour $11: 30$ ) is a positive surge, generated by the discharge at the lock in Mettlach $11.6 \mathrm{~km}$ upstream. On average, 18 lock operations were performed per day and each locking event is associated with the generation of such a wave, which superimpose while traveling with an approximate phase speed of $6.6 \mathrm{~m} \mathrm{~s}^{-1}$ back and forth through the impoundment (A. Maeck and A. Lorke, Ship-lock induced waves in an impounded river and their impact on sub-daily velocity fluctuations, submitted to River Research and Applications, 2012; henceforth Maeck and Lorke, submitted). Mean current speed during time periods of lock operation (see section 3.2) was $4.0 \mathrm{~cm} \mathrm{~s}^{-1}$, during time periods without lock operation it was reduced to $2.8 \mathrm{~cm} \mathrm{~s}^{-1}$. 


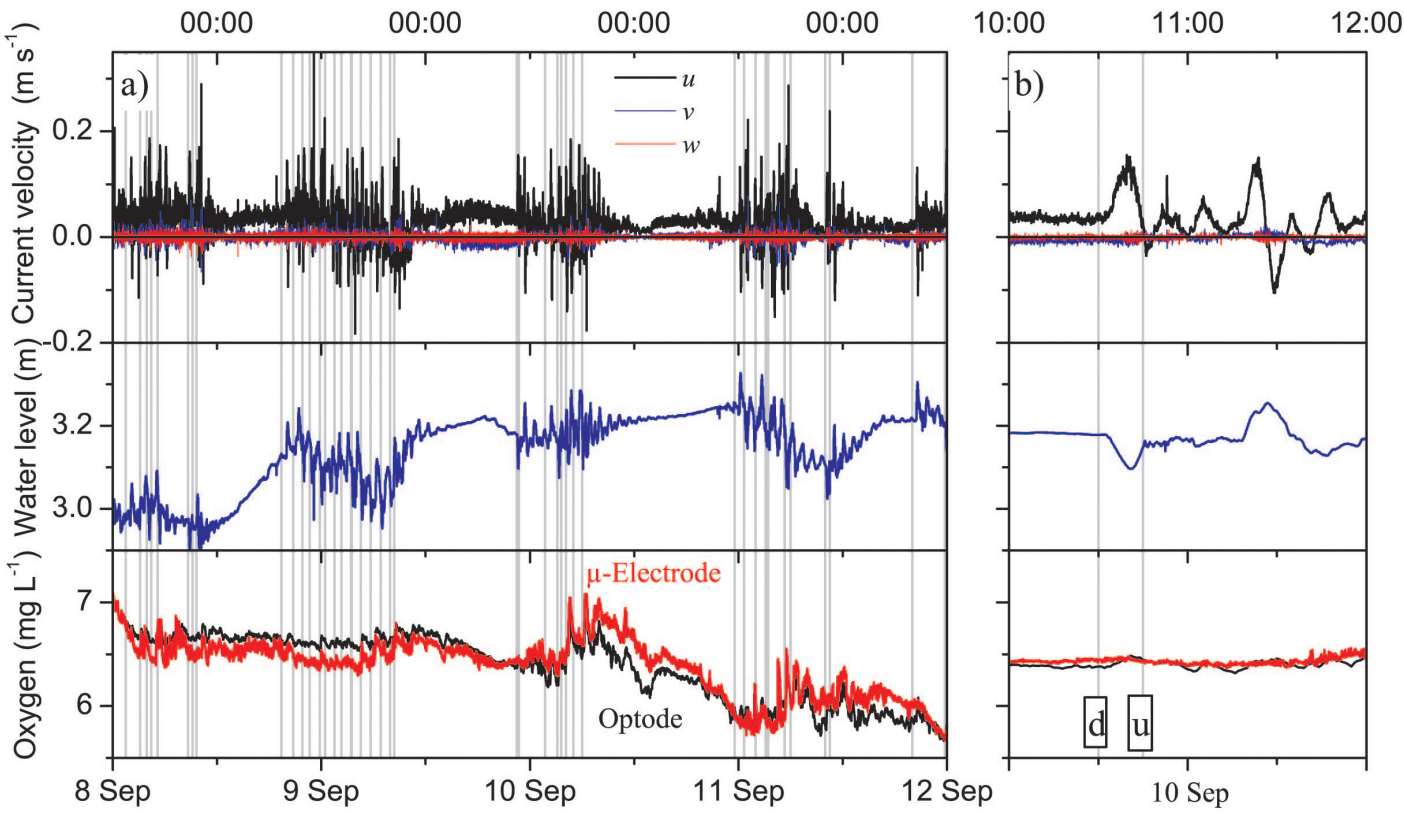

Figure 2. (a) Time series of current velocity [upper panel, longitudinal ( $u$ ), transversal $(v)$, and vertical (w) components], water level (middle panel, depth at the benthic lander site), and dissolved oxygen concentrations measured by the optode and the microelectrode (lower panel). Gray vertical lines denote times of upstream or downstream lock operation. (b) Same as (a) but zooming on the first two locking events on 10 September [scaling of ordinates is identical to (a), the black brackets at the top and bottom axes in (a) encompass the time period shown in (b)]. The first locking event $(u)$ refers to an upstream locking at the lock Serrig (1.3 km down from the sampling site), the second event $(d)$ was an downstream locking event at Mettlach (11.6 km upstream of the sampling site).

[16] Besides the daily pattern of wave-induced fluctuations, low-frequency changes of water level are associated with discharge variations due to hydropower generation and cumulative lock discharge. DO concentrations of dissolved oxygen decreased slowly from $\approx 7$ to $\approx 6 \mathrm{mg} \mathrm{L}^{-1}$, corresponding to $\sim 60 \%$ saturation (Figure 2). Waveinduced variations of oxygen concentration are predominantly small, indicating horizontal homogeneity.

[17] The intensity of bottom-boundary layer turbulence, expressed as dissipation rates of turbulent kinetic energy (Figure 3), varies between $10^{-10}$ and $10^{-6} \mathrm{~W} \mathrm{~kg}^{-1}$ and are related to mean flow velocity and locking activity.

\subsection{Oxygen Flux}

[18] Vertical oxygen fluxes, estimated for time series segments of $512 \mathrm{~s}$, show strong fluctuations between $-1 \times$ $10^{-4}$ and $2 \times 10^{-5} \mathrm{~g} \mathrm{~m}^{-2} \mathrm{~s}^{-1}$ (Figure 3), where negative fluxes are downward, i.e., into the sediment, and positive fluxes are directed upward. The mean oxygen flux, if averaged over the entire period of observation, is $(-1 \pm 1.6) \times$ $10^{-5} \mathrm{~g} \mathrm{~m}^{-2} \mathrm{~s}^{-1}$ (mean $\pm \mathrm{std}$ ), corresponding to $-0.9 \mathrm{~g}$ $\mathrm{m}^{-2} \mathrm{~d}^{-1}$ or $-28 \mathrm{mmol} \mathrm{m}^{-2} \mathrm{~d}^{-1}$.

[19] Visual inspection of the high-resolution oxygen fluxes in Figure 3 suggests that the oxygen fluxes are also strongly affected by ship locking. To analyze the relationship between lock operation and oxygen flux, the complete time series of measured fluxes were divided into segments with and without locking (Figure 3). Segments with locking are initiated by one lock operation (usually the first locking event in the morning), and extended until $2 \mathrm{~h}$ after the last

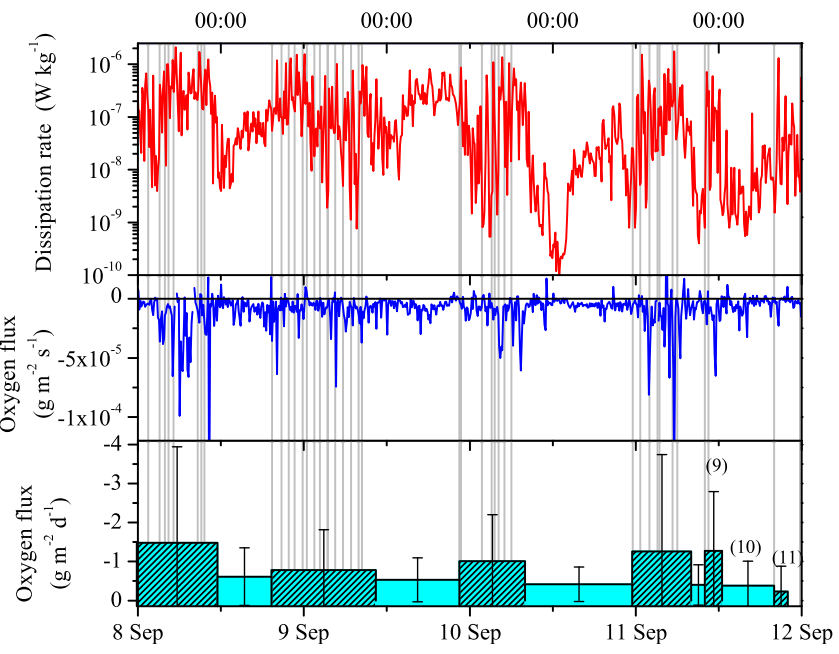

Figure 3. Time series of dissipation rates of turbulent kinetic energy (upper panel), sediment-water oxygen fluxes (middle panel, $512 \mathrm{~s}$ estimates), and mean sediment oxygen flux (lower panel), averaged over periods of locking activity (dashed bars, width of bars corresponds to averaging interval, error bars show standard deviation) and inactivity (no pattern), respectively. Note that the error bars are symmetrical around the mean value, but only negative fluxes are shown. Gray vertical lines denote times of upstream or downstream lock operation. The bottom axis shows date in 2010, time of day is provided by the upper axis. Labeled data point in the lower panel $(9,10,11)$ are discussed in the text. 
lock operation to ensure that they include the damping period of the lock-induced waves. While the mean flux during time periods with lock operation was $-1.0 \pm 0.5 \mathrm{~g} \mathrm{~m}^{-2} \mathrm{~d}^{-1}$, it was significantly reduced by about a factor of 2 to $-0.5 \pm$ $0.1 \mathrm{~g} \mathrm{~m}^{-2} \mathrm{~d}^{-1}$, within data segments with no ship locking. Statistical significance was tested using the Wilcoxon rank sum test $(p<0.001, n=316 / 343)$.

\subsection{Turbulence-Driven Sediment Oxygen Uptake}

[20] The segment mean values obtained for contiguous time periods with and without lock operation (Figure 3) are used to analyze the interrelation between the observed hydrodynamics and oxygen fluxes. The observed current speed is correlated with dissipation rates of turbulent kinetic energy (Figure 4a). For current speeds exceeding $\sim 3 \mathrm{~cm} \mathrm{~s}^{-1}$, dissipation rates $\varepsilon$ scale with the one-third power of current speed $\left(\sim \varepsilon^{1 / 3}\right)$, indicating validity of the law of the wall [Wüest and Lorke, 2003].

[21] Lorke and Peeters [2006] showed that the transfer velocity of solute exchange across the sediment-water interface is related to the dissipation rate of turbulent kinetic energy and that under law of the wall conditions (logarithmic velocity profile), the flux $F$ for a given concentration gradient scales with $\sim \varepsilon^{1 / 3}$. This implies that the sediment-water oxygen flux in aquatic systems with high sediment oxygen demand, e.g., in eutrophic systems, is controlled by the thickness of the diffusive sublayer overlaying the sediment surface, which in turn is a function of the intensity of boundary layer turbulence. The flux $F$ across the diffusive boundary layer can be expressed as the product of a transfer velocity $k(k=D / \delta, D$ is the molecular diffusion coefficient of DO and $\delta$ is the thickness of the diffusive sublayer) and the concentration gradient $\Delta C(F=$ $k \cdot \Delta C)$. Although the concentration gradient at the sediment-water interface was not measured in our observations and is likely to vary over time, observed mean fluxes follow this scaling relation, at least as an order of magnitude estimate (Figure 4b).

[22] Besides turbulence, DO fluxes may also be affected by sediment resuspension. Acoustic backscatter measured by the ADV was higher during time periods of lock operations (Figure 4c), and if averaged over contiguous time periods of lock operation, eddy-correlation oxygen fluxes also increase with increasing acoustic backscatter strength. The correlation between acoustic backscatter strength and oxygen flux is particularly strong with few exceptions for short contiguous averaging intervals [e.g., flux estimates labeled (9) and (11) in Figure 3].

\section{Discussion}

[23] We have analyzed a 4 day long continuous record of sediment-water fluxes and boundary layer turbulence in an impounded river with a major focus on the temporal variations of sediment oxygen uptake. Average fluxes as well as flux variability show a pronounced diurnal pattern. Mainly during daytime, amplitudes of flux variations can exceed the mean flux by a factor of 10 . These strong variations are associated with the operation of the ship locks located upstream and downstream of the sampling site. Filling and discharge of the locks release 36,000 and $27,000 \mathrm{~m}^{3}$ of water, respectively, and generate surges, which propagate along the impoundment and are reflected at both dams (Maeck and Lorke, submitted). Each passage of these waves at the sampling site is associated with elevated near-bed current velocities and rates of turbulent kinetic energy dissipation. The daily schedule of lock operations results in a doubling of mean sediment uptake rates of dissolved oxygen during daytime. Mean oxygen fluxes toward the sediment $F$ increase with turbulent kinetic energy dissipation $\varepsilon\left(F \sim \varepsilon^{1 / 3}\right)$, as is predicted by the scaling of interfacial fluxes across a diffusive boundary layer whose thickness is controlled by the intensity of turbulence in the overlying water [Lorke and Peeters, 2006].

[24] The overall mean flux of dissolved oxygen into the sediment is $\sim-1 \mathrm{~g} \mathrm{~m}^{-2} \mathrm{~d}^{-1}$, which is within the range of fluxes measured in the past at the same site using chamber $\left(-0.6\right.$ to $\left.-4.9 \mathrm{~g} \mathrm{~m}^{-2} \mathrm{~d}^{-1}\right)$ and microprofiling $\left(-2.1 \mathrm{~g} \mathrm{~m}^{-2} \mathrm{~d}^{-1}\right)$ techniques (V. Kirchesch, unpublished data). The observed mean flux agrees also very well with the sediment oxygen consumption rate of $-0.9 \mathrm{~g} \mathrm{~m}^{-2} \mathrm{~d}^{-1}$
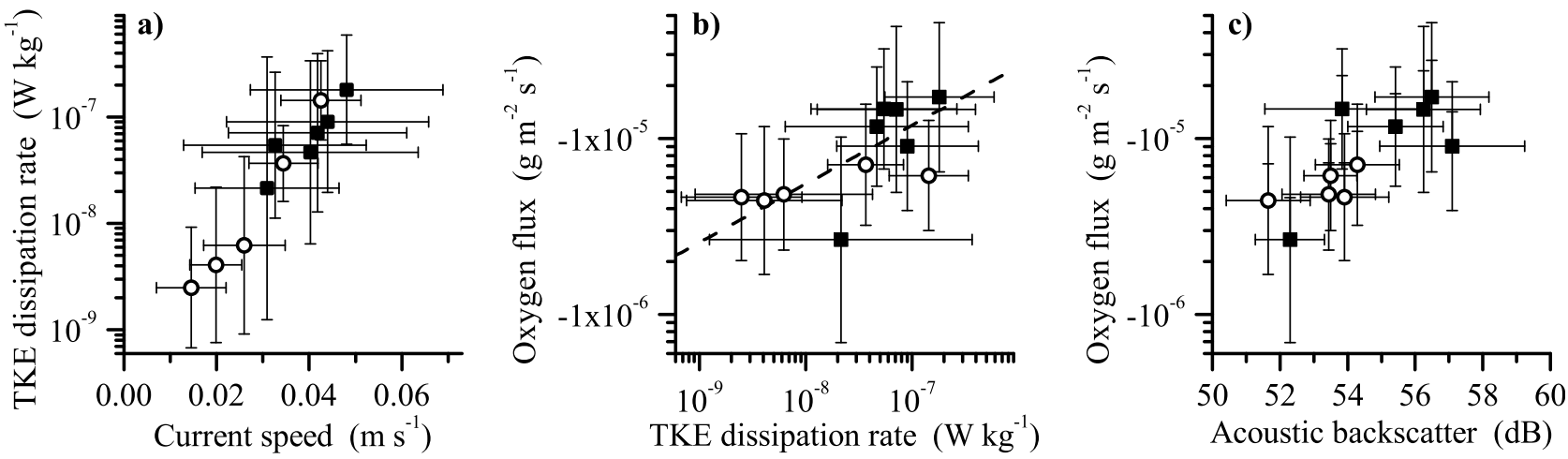

Figure 4. Relationships between segment mean values of (a) current speed and dissipation rates of turbulent kinetic energy (TKE), (b) TKE dissipation rate and eddy-correlation oxygen flux, and (c) acoustic backscatter strength (relative units) measured by the ADV and oxygen flux. Open symbols $(\bigcirc)$ are mean values averaged over time periods without lock operation; filled symbols $(\boldsymbol{\square})$ correspond to periods with lock operation (cf. Figure 3). Error bars show standard deviations within each segment. The dashed line in (b) shows the theoretical relationship derived for fluxes across a diffusive sublayer, which thickness is controlled by boundary layer turbulence. 
estimated for the impoundment Serrig by Becker et al. [2010] using the water quality model QSim. These numerical simulations further revealed that the majority of oxygen consumption in the impoundment is occurring in the water column and is associated with nitrification $(59 \%$ of total oxygen consumption) and degradation of organic carbon $(19 \%)$. Because the sediment is a major source for ammonium as well as labile or dissolved organic carbon in the water column, rates of oxygen consumption within the water column can be assumed to be affected by the transfer velocity at the sediment-water interface. The impact of temporal variations of the transfer velocity caused by ship locking on the water column oxygen balance in the impoundment may hence be much stronger than observed with the sediment-water oxygen fluxes. Also not included in our flux measurements is the local effect of passing ship traffic. Each pair of upstream and downstream lock operation is associated with the passage of at least one ship at the sampling site and the short-term occurrence of ship-induced surface waves. Due to their high frequency [Hofmann et al., 2008], these waves could not be resolved by the dissipation and eddycorrelation flux measurements, but potentially constitute an additional enhancement of sediment-water exchange rates.

[25] The observed increase of acoustic backscatter strength with increasing current speed in our measurements indicates sediment resuspension [Hofmann et al., 2011], with these high current speeds mainly associated with the passage of lock-induced waves. As demonstrated in a recent study by Waterman et al. [2011], suspended sediment can contribute substantially to oxygen consumption within the water column and thus provide an additional means by which exchange processes at the sediment-water interface affect water column DO budgets, which is not resolved in direct flux measurements. In addition, dissolved methane, which is produced by anaerobic microbial degradation of organic carbon within the sediment, was demonstrated to be the second most important reduced substance in terms of water column oxygen consumption in eutrophic lakes [Matzinger et al., 2010]. Furthermore, extensive methane accumulation within the sediment can lead to ebullition [Boudreau et al., 2005]. Visual observations at the sampling site revealed the regular occurrence of massive bubble outbursts, potentially triggered by variations of pressure and bottom shear associated with the passage of lock-induced waves and large cargo ships. Bubble rise within the sediments is associated with enhanced pore water mixing [Haeckel et al., 2007] and ebullition can be expected to cause resuspension of surface sediments and enhancement of solute exchange across the sediment-water interface.

\section{Conclusions}

[26] High-resolution measurements of sediment-water oxygen flux in an impounded river revealed the pronounced modulation by ship locking. The observations indicate that in impounded rivers the magnitude and temporal variability of oxygen uptake, including the flux of oxygen into the sediment, the flux of reduced substances from the sediment to the water column, as well as particle or bubble-mediated transport, are, to some extent, influenced by operational and management activities. Taking into account that many rivers are engineered for shipping purposes, it can be expected that metabolism and oxic conditions in these rivers are potentially affected not only by the morphological changes made, but also by the operation of ships and waterway navigation structures. Detailed understanding of the underlying flux paths and their dependence on hydrodynamic driving forces, provide the opportunity to extrapolate our observations using coupled hydrodynamic and water quality models. In the future, such models can be used to simulate operation of navigation infrastructure for optimum water-quality management in river systems.

[27] Acknowledgments. We gratefully acknowledge support by the Waterways and Shipping Office Saarbrücken during instrument deployment and recovery. Thanks to Anni Glud for providing the microelectrodes used in this study and Sergiy Cherednichenko for assisting with the eddy lander. An earlier draft of the manuscript was improved by the helpful comments of three anonymous reviewers. This study was financially supported by the German Research Foundation (DFG; LO 1150/5-1), and by the National Environmental Research Council (NERC; NE/F012691/1).

\section{References}

Alin, S. R., M. Rasera, C. I. Salimon, J. E. Richey, G. W. Holtgrieve, A. V. Krusche, and A. Snidvongs (2011), Physical controls on carbon dioxide transfer velocity and flux in low-gradient river systems and implications for regional carbon budgets, J. Geophys. Res. Biogeosci., 116, G01009.

Archer, D., S. Emerson, and C. R. Smith (1989), Direct measurement of the diffusive sublayer at the deep sea floor using oxygen microelectrodes, Nature, 340, 623-626.

Becker, A., V. Kirchesch, H. Baumert, H. Fischer, and A. Schöl (2010), Modelling the effects of thermal stratification on the oxygen budget in an impounded river, River Res. Appl., 26, 572-588.

Berg, P., H. Røy, F. Janssen, V. Meyer, B. B. Jørgensen, M. Hüttel, and D. de Beer (2003), Oxygen uptake by aquatic sediments measured with a novel non-invasive eddy-correlation technique, Mar. Ecol. Prog. Ser., 261, 75-83.

Berg, P., H. Røy, and P. L. Wiberg (2007), Eddy correlation flux measurements: The sediment surface area that contributes to the flux, Limnol. Oceanogr., 52(4), 1672-1684.

Bluteau, C. E., N. L. Jones, and G. N. Ivey (2011), Estimating turbulent kinetic energy dissipation using the inertial subrange method in environmental flows, Limnol. Oceanogr. Method, 9, 302-321.

Bosch, N. S., and J. D. Allan (2008), The influence of impoundments on nutrient budgets in two catchments of Southeastern Michigan, Biogeochemistry, 87(3), 325-338.

Boudreau, B. P., C. Algar, B. Johnson, I. Croudace, A. Reed, Y. Furukawa, K. M. Dorgan, P. A. Jumars, A. S. Grader, and B. S. Gardiner (2005), Bubble growth and rise in soft sediments, Geology, 33, 517-520.

Brand, A., D. F. McGinnis, B. Wehrli, and A. Wüest (2008), Intermittent oxygen flux from the interior into the bottom boundary of lakes as observed by eddy correlation, Limnol. Oceanogr., 53(5), 1997-2006.

Friedl, G., and A. Wuest (2002), Disrupting biogeochemical cyclesConsequences of damming, Aquat. Sci., 64(1), 55-65.

Glud, R. N., P. Berg, A. Hume, P. Batty, M. E. Blicher, K. Lennert, and S. Rysgaard (2010), Benthic $\mathrm{O}_{2}$ exchange across hard-bottom substrates quantified by eddy correlation in a sub-Arctic fjord, Mar. Ecol. Prog. Ser. $417,1-12$.

Grant, S. B., and I. Marusic (2011), Crossing turbulent boundaries: Interfacial flux in environmental flows, Environ. Sci. Technol., 45(17), 71077113.

Haeckel, M., B. P. Boudreau, and K. Wallmann (2007), Bubble-induced porewater mixing: A 3-D model for deep porewater irrigation, Geochem. Cosmochin. ACTA, 71(21), 5135-5154.

Hofmann, H., A. Lorke, and F. Peeters (2008), The relative importance of wind and ship waves in the littoral zone of a large lake, Limnol. Oceanogr., 53, 368-380.

Hofmann, H., A. Lorke, and F. Peeters (2011), Wind and ship waveinduced resuspension in the littoral zone of a large lake, Water Resour. Res., 47(9), W09505, doi:10.1029/2010WR010012. 
Kittrell, F. W., S. L. Jones, and R. S. Ingols (1959), Effects of impoundments on dissolved oxygen resources [with Discussion], Sewage Ind. Wastes, 31(9), 1065-1081.

Lorke, A., and F. Peeters (2006), Toward a unified scaling relation for interfacial fluxes, J. Phys. Oceanogr., 36, 955-961.

Lorke, A., and A. Wüest (2005), Application of coherent ADCP for turbulence measurements in the bottom boundary layer, J. Atmos. Ocean. Technol., 22, 1821-1828.

Lorke, A., B. Müller, M. Maerki, and A. Wüest (2003), Breathing sediments: The control of diffusive transport across the sediment-water interface by periodic boundary-layer turbulence, Limnol. Oceanogr., 48(6), 2077-2085.

Lorrai, C., D. F. McGinnis, P. Berg, A. Brand, and A. Wuest (2010), Application of oxygen eddy correlation in aquatic systems, J. Atmos. Ocean. Technol., 27(9), 1533-1546.

Matzinger, A., B. Muller, P. Niederhauser, M. Schmid, and A. Wuest (2010), Hypolimnetic oxygen consumption by sediment-based reduced substances in former eutrophic lakes, Limnol. Oceanogr., 55(5), 2073-2084.

McGinnis, D. F., S. Bocaniov, C. Teodoru, G. Friedl, A. Lorke, and A. Wüest (2006), Silica retention in the Iron Gate I Reservoir on the Danube River: The role of side bays as nutrient sinks, River Res. Appl., 22, 441-456.

McGinnis, D. F., P. Berg, A. Brand, C. Lorrai, T. J. Edmonds, and A. Wüest (2008), Measurements of eddy correlation oxygen fluxes in shallow freshwaters: Towards routine applications and analysis, Geophys. Res. Lett., 35, L04403, doi:10.1029/2007GL032747.
McGinnis, D. F., S. Cherednichenko, S. Sommer, P. Berg, L. Rovelli, R. Schwarz, R. N. Glud, and P. Linke (2011), Simple, robust eddy correlation amplifier for aquatic dissolved oxygen and hydrogen sulfide flux measurements, Limnol. Oceanogr. Methods, 9, 340-347.

Nilsson, C., C. A. Reidy, M. Dynesius, and C. Revenga (2005), Fragmentation and flow regulation of the world's large river systems, Science, 308(5720), 405-408.

Reidenbach, M. A., M. Limm, M. Hondzo, and M. T. Stacey (2010), Effects of bed roughness on boundary layer mixing and mass flux across the sediment-water interface, Water Resour. Res., 46, W07530, doi:10.1029/ 2009WR008248.

Rosenberg, D. M., R. A. Bodaly, and P. J. Usher (1995), Environmental and social impacts of large scale hydroelectric development: Who is listening?, Glob. Environ. Change Human Policy Dimens., 5(2), $127-148$.

Stamm, J. (2003), Impoundments in rivers - Considerations from a waterways engineering point of view, in Staugeregelte Flüsse in Deutschland, edited by D. Müller, et al., pp. 1-18, Schweizerbart, Stuttgart.

Waterman, D. M., A. R. Waratuke, D. Motta, Y. A. Catano-Lopera, H. Zhang, and M. H. Garcia (2011), In situ characterization of resuspended-sediment oxygen demand in Bubbly Creek, Chicago, Illinois, J. Environ. Eng., 137(8), 717-730.

Wilczak, J. M., S. P. Oncley, and S. S. Stage (2001), Sonic anemometer tilt correction algorithms, Boundary-Layer Meteorol., 99, 127-150.

Wüest, A., and A. Lorke (2003), Small-scale hydrodynamics in lakes, Annu. Rev. Fluid Mech., 35, 373-412. 